Донченко А. И.

A. I. Donchenko

ПСЕВДОНАРОДНЫЕ И СОЦИАЛЬНЫЕ СЮЖЕТЫ В МЕРОВИНГСКОЙ АГИОГРАФИИ (ЧАСТЬ II)

\title{
PSEUDONATIONAL AND SOCIAL SUBJECTS IN MEROVINGIAN HAGIOGRAPHY (PART II)
}

Донченко Алексей Иванович - доктор культурологии, профессор кафедры всеобщей истории, философии и культурологии Благовещенского государственного педагогического университета (Россия, Благовещенск). E-mail: alexdon@mail.ru.

Mr. Alexey I. Donchenko - Dr. hab. of Culture Studies, Professor, General History, Philosophy, Culture studies department, Blagoveshchensk State pedagogical University (Russia, Blagoveshchensk). E-mail: alexdon@mail.ru.

Аннотация. В данной статье автор выявляет особенности сюжетов и мотивов агиографической литературы эпохи Меровингов. Автор приходит к выводу о том, что литература данной эпохи носит в большей степени церковно-монастырский характер и не имеет тесной связи с подлинно народным творчеством.

Summary. In this article the author reveals the plots and motives of Merovingian hagiographic literature. The author comes to the conclusion that the literature of this epoch is, to a greater extent, ecclesiastical and monastic in nature and has little to do with genuinely folk art.

Ключевые слова: эпоха Меровингов, христианство, агиография, жития святых, фольклор, сказка, литературный персонаж.

Key words: the era of the Merovingians, Christianity, hagiography, the lives of saints, folklore, fairy tale, literary character.

УДК 008 (8)

Псевдонародные мотивы встречаются в меровингских произведениях не слишком часто. Намного чаще, можно сказать в подавляющем большинстве, в них используются социальные моmивы, в которых автор выражает своё отношение к общественным проблемам своего времени. Эти мотивы проявляются не во всех легендах и не во всех их составных частях с одинаковой выразительностью. Зачастую они выражаются сильней в сообщениях о чудесах (miracula), предназначенных для простых слушателей, чем в житиях (vitae), предназначенных для монастырей. Различны они и по отношению к отдельным типам святых. Далёкий от мира затворник и аскет заботится лишь о спасении собственной души; окружающий мир ему безразличен. Отвергая его, он противостоит ему. Мирские проблемы, и социальные в том числе, ему неинтересны. Для монаха социальные мотивы также играют незначительную роль: он живёт в монастырском сообществе, и в стенах монастыря подобные мотивы и не могли возникать. Иначе обстоит дело со святым аббатом или аббатисой, которые отвечают за монастырскую общину, ведь монастырь, помимо всего прочего, выполняет и социальную функцию. Он кормит бедных, принимает странников и пилигримов; он должен быть основным местом благотворительной деятельности. Своего апогея эти мотивы достигают в легендах о святых епископах, пребывающих и действующих в гуще жизни, святых, которым была поручена особая забота о бедных, больных и угнетённых в своих диоцезах. Поэтому во многих легендах о епископах мы находим демонстративное подчёркивание социальных мотивов (см. прим. 1).

Внутри христианского сообщества не должно быть никаких социальных различий, все должны быть равными - идеал, столь излюбленный древней церковью. Но те времена давно прошли, равенство верующих осталось только в теории, на практике же от него давным-давно отказались. Христиане в социальном плане были расколоты, и в приходах оказались бедные и богатые, 
Донченко А. И.

ПСЕВДОНАРОДНЫЕ И СОЦИАЛЬНЫЕ СЮЖЕТЫ В МЕРОВИНГСКОЙ АГИОГРАФИИ (ЧАСТЬ II)

угнетённые и господа, которые поклонялись одному христианскому Богу. Церковь, особенно агиография, должны были занять в этом вопросе какую-либо позицию.

В литературе этого времени прежде всего господствует древнее противостояние бедный богатый. В эту переходную эпоху оно оказалось доминирующим противоречием в обществе и оставалось таковым в сознании людей на протяжении средневековья. Отчётливо противоречия между бедными и богатыми проявляются в Ветхом Завете, где пророки восстают против жестокосердных богачей и проповедуют милосердие к бедным. Однако в Новом Завете звучит проклятие богатству; и потому «удобнее верблюду пройти сквозь игольные уши, нежели богатому войти в Царствие Божие» (Мф. 19, 24), а осуждение богатых в Послании Иакова (Иак. 5) достигает визионерско-профетического пафоса.

Некоторые Отцы церкви также проклинали богатство, видя в основе его происхождения явления несправедливости и грабежей. Но эти голоса становились слабее по мере того, как сама церковь становилась богаче, и потому постепенно ослабевало утверждение о богатстве как опасности для спасения души. Рука об руку с этим идёт процесс прославления бедности, поскольку Христос прославляет бедных (см. прим. 2), и, как известно, в качестве своих апостолов Он избирает бедных, простых людей (см. прим. 3). Прославление бедности господствовало в средневековых произведениях до появления городской литературы, которая, как и фольклор, увидела в бедности отнюдь не достоинство, а проявление злой судьбы.

Вскоре церковное учение ограничивает смысл образа блаженного бедняка и при этом подчёркивает, что прославляются «бедные духом» (см. прим. 4). Августин предостерегает от превозношения бедности (см. прим. 5). Напротив, агиография в этом отношении более прямолинейна, её симпатии полностью на стороне бедных, но тех бедных, которые стали ими Христа ради. Лишь изредка здесь появляется «нищий духом», и только в отдельных случаях в агиографии проявляется известный народный мотив, когда бедность выступает как наказание, а богатство - как награда (см. прим. 6). Обычно в агиографии господствует абсолютное прославление бедности.

В церковных произведениях также решительным образом отстаивается точка зрения о неважности различия между бедностью и богатством. И здесь речь идёт либо о чисто «светской» идее о том, что в действительности бедняк гораздо счастливее богача, постоянно пребывающего в страхе за своё богатство, либо (чисто по-христиански) окончательное воздаяние обоим переносится в потусторонний мир. История о Лазаре - очень популярный мотив католических проповедников; в Галлии его неоднократно использовал Цезарий Арелатский, однако в агиографии он употреблялся довольно редко; авторы легенд не очень любят социально-уравнительные истории и теоретические спекуляции на эту тему.

В социальном плане центральный мотив, популярный в церковной литературе и особенно в агиографии, - это благотворительная деятельность богатых и церкви. Милостыня искупает грехи (см. прим. 7), с её помощью богач тоже может достичь царствия небесного; епископ, особенно святой, должен заботиться о бедных, и он это делает, раздавая милостыню.

Церковь действительно проявляла заботу о бедных, и было бы верхом несправедливости приуменьшать значение этой деятельности, ибо в то время церковь была единственной организацией, занимающейся решением подобных вопросов. Конечно, полностью устранить бедность как общественное явление она не могла, ибо вообще никакая благотворительная деятельность не может (да и не стремится) это сделать. Но больным и старым, нуждающимся и чужеземцам без помощи церкви было бы обойтись чрезвычайно трудно. Подаяние бедным - это богоугодное дело, и эпитет pauperibus largus (щедрый к бедным) употребляется в качестве прославления той или иной личности. Святой, конечно, делает щедрые подаяния бедным, иногда он в больших объёмах использует для этого церковные средства или основывает специальные приюты-больницы для бедных. Но для святого этого недостаточно. По библейской заповеди он должен отказаться от всего своего имущества и, по возможности, раздать его бедным. Он отрекается от мира, оставляет имущество и богатство, раздаёт всё нуждающимся, и это не воспринимается им как некий великий подвиг, после этого он даже не вспоминает об утерянном богатстве. Но и этого для святого и агиографии мало. Святой отдаёт бедным даже свою одежду (см. прим. 8) - всё, что ему подарили или 


\section{Учёные записки}

Комсомольского-на-Амуре государственного технического университета

что он сумел выпросить в качестве подаяния (см. прим. 9). Он презирает светский лоск, избегает его, и последнее слово этого идеала - святой как нищий, явление, которое позже станет особенно популярным благодаря св. Франциску. Внутреннее стремление к такому идеалу бедности было настолько сильным, что он проник во франкские легенды и создал в них тип святого нищего, хотя в своей основе этот тип был совершенно чужд франкской епископальной церкви.

Святой аббат Сигирамн согласно его житию (см. прим. 10) был очень знатного рода. Какоето время он даже находился при дворе короля и в итоге стал аббатом. Но когда несколько монахов составили против него заговор, он покинул монастырь, однако не стал основывать новый (как это сделал в своё время св. Бенедикт), а предпочёл скитаться по стране в изношенной одежде, нищенствуя, раздавая полученное подаяние и помогая бедным в их работе. Вершина идеала бедности была достигнута.

Идеал бедности, радость подачи милостыни полностью господствуют в меровингской литературе. Святой меровингской эпохи совершенно беден: всё, что у него есть, раздаёт нищим. Щедрая раздача милостыни, забота о бедных делают его идеальным примером благотворительности.

Однако святой приближается к простому народу не только посредством невзыскательности и бедности, но и тем, что он трудится, поскольку в Библии есть заповедь: «Если кто не хочет трудиться, тот и не ешь» (см. прим. 11). Работа известна и героям сказки, и героям героической саги: они тоже должны иногда работать (правда, они идут на это не по своей воле), но они быстро повышают свой социальный статус и избавляются от этой обузы. Иначе обстоит дело в агиографии, где труд является своего рода добровольным умерщвлением плоти. Монастырские уставы требуют от насельников монастырей телесной работы, и, соответственно, в житиях трудятся монахи и монахини, аббаты и аббатисы (см. прим. 12). Конечно, возможности для работы в монастыре и в житиях весьма ограничены: монахи трудятся в поле или корчуют лес, монахини посвящают себя заботам о больных (интересно, что святых-ремесленников эта эпоха почти не знает). Святой также может находиться в услужении, как это имеет место с рабом Митрой, с Винценцианом, который вынужден был служить на конюшне или с верной служанкой Лиутбиргой. Святые прислуживали в том случае, когда они брали на себя этот труд добровольно. Они лично прислуживали бедным во время еды, мыли гостям ноги, ухаживали за прокажёнными и даже прислуживали рабам. Труд - это один из инструментов аскезы, и чем унизительней он был, тем больше представлялась заслуга святого, тем больше он демонстрировал своё смирение.

Идеал бедности и идея о том, что работа является составной частью аскезы, в агиографии защищались много убедительнее и настойчивее, чем в остальных церковных произведениях. Но это настоятельное подчёркивание не объясняет проникновения в агиографию народных представлений, которым неизвестно ни прославление бедности, ни работа как умерщвление плоти (см. прим. 13). Примечательно то, что сказка намного критичнее социально, чем житие, основные черты которого были подчинены идеалу благотворительности. В этом отношении агиография также совершенно чужда народу, однако по-своему она обращена к рядовым мелким крестьянам, ремесленникам и беднякам. Святые отрекаются от всех житейских благ, они раздают милостыню, заботятся о нуждающихся и иногда даже помогают в повседневном труде. В результате посредством таких, совершенно «чуждых народу», средств они становятся ближе к нему.

Однако нищета была далеко не единственной социальной проблемой, определявшей повседневную жизнь того времени. Эпоха Меровингов - это время, когда в общественных отношениях зачастую царит грубая, неприкрытая сила. Эта эпоха была далека от того, чтобы её можно было определить словом «право», и власть имущие весьма часто использовали силу для подавления и лишения прав своих бедных сограждан, а раб практически полностью находился в руках своего господина. Угнетение бедных и слабых осуждается уже в Ветхом Завете (9см. прим. 14), но в церковных произведениях мы лишь изредка находим литературное развитие этого мотива. В определённой степени теологи всё же были озабочены проблемой угнетения бедных, но данный мотив редко использовался для самостоятельных рассказов, ибо, благословив восстание против угнетателей, против власть имущих, церковь оказалась бы в противостоянии с властвующими, с «государством», а этого она не могла себе позволить по ряду понятных причин. Именно поэтому появ- 
Донченко А. И.

ПСЕВДОНАРОДНЫЕ И СОЦИАЛЬНЫЕ СЮЖЕТЫ В МЕРОВИНГСКОЙ АГИОГРАФИИ (ЧАСТЬ II)

ление в агиографии святого, противостоящего угнетателям, наблюдается очень редко. И хотя в агиографии властители (см. прим. 15) или скупые богачи (см. прим. 16) наказываются довольно часто, это происходит только тогда, когда они выступают против святого или его церкви, ибо святой в легенде защищает своё имущество от посягательств других лиц - мотив, пропагандистская функция которого настолько очевидна, что нет особой необходимости подчёркивать это ещё раз.

Особенно жалкой была участь невольников, их количество непрестанно росло в результате войн и набегов. Агиография была вынуждена занять определённую позицию и по этому вопросу, но всё же она заставляет святого не бороться против угнетателей, а лишь смягчать последствия угнетения. Такова позиция церкви и агиографии по отношению к правосудию того времени, которое отличалось немалой жестокостью. Эта жестокость была обусловлена не только собственно наказаниями, но и системой высоких штрафов, которые были чрезмерными для бедняков, а кроме того, большим количеством разного рода юридических бумаг, которыми простым смертным было трудно обзавестись. Судебные разбирательства проводились с грубым произволом и зачастую имели своим следствием жестокие наказания. Церковь, правда, подчёркивала необходимость справедливости судей и особенно господ и возлагала на епископов обязанность брать под защиту бедняков, вдов и сирот, но эти идеи ещё не получили должного развития в литературе. И всё же лишь в единичных случаях подвергается сомнению сама возможность добиться правого суда (см. прим. 17) и примечательным образом из меровингской агиографии полностью исчезает образ злого, несправедливого судьи, игравшего большую роль в актах мучеников, особенно в сказаниях о них. Конечно, судья в агиографии тоже по-своему жесток, тираничен, он являет собой полную противоположность кроткого и доброго святого. Однако его жестокость - это неумолимое исполнение действующего «закона», а не произвол и несправедливость.

В этом отношении агиография отличается от остальных церковных произведений и от церковной практики. Святой выкупает пленных или чудесным образом освобождает заключённых, невзирая на их виновность или невиновность. Он постоянно заступается за беглеца, он даже принимает беглых невольников, хотя теоретически резко осуждает такие побеги. Церковные законы даже ограничивали право убежища для таких лиц (см. прим. 18), а монастыри преследовали своих бежавших невольников путём «объявления розыска». Иначе поступает святой: он освобождает заключённых и невольников, он является воплощением христианской кротости, которая и не питает вражды к судье (как в сказаниях о мучениках), но благотворным образом смягчает последствия приговора, при этом святой выкупает и освобождает даже заключённых, приговорённых к виселице.

Иное отношение у святого и к вору. На практике преступления, связанные с посягательством на собственность, в большинстве случаев на протяжении всей феодальной эпохи карались смертной казнью. Однако святой в церковной литературе ведёт себя иначе. Хотя он и наказывает вора, посягнувшего на его собственность (см. прим. 19), но это наказание похоже на пристыжение и обычно не имеет далеко идущих последствий. Наказания же светской власти святой, как правило, может предотвратить. При помощи чуда с повешенным он может добиться освобождения даже самого отпетого разбойника (см. прим. 20) и таким же образом избегает смерти вор, которого привели на виселицу необдуманные слова священника (см. прим. 21). Позднее святые-властители обязаны были не наказывать вора, а давать ему возможность совершить кражу и бежать.

Таким образом, агиография заставляет действовать святых благотворительно, смягчать последствия угнетения, «правосудия» и бедности. Святой - типично христианский «герой»; он не борется против несправедливости, а предотвращает её последствия. Намного убедительнее остальных источников агиография подчёркивает «социальные мотивы», и в этом её идеи частично отличаются даже от повседневной практики церкви. Своими рассказами агиография обращается к народу, которому демонстрируется благотворительно действующий святой, по воле Божьей отказавшийся от всех благ, живущий беднее и аскетичнее самого последнего нищего, но больше всех готовый всегда прийти на помощь. Он, добровольно став бедным, щедро раздаёт милостыню, присматривает за больными и неимущими, освобождает заключённых, заботится о вдовах и сиротах. Он является не только могущественным покровителем в борьбе с враждебными сверхъестественными силами, которые постоянно угрожали человеку и делали окружающую его действи- 


\section{Учёные записки}

Комсомольского-на-Амуре государственного технического университета

тельность небезопасной, святой одновременно является фактически главным помощником во всех социальных нуждах, а церкви и монастыри в то время были действительно единственными организациями, которые заботились о бедных и заключённых.

Итак, агиография стилизует святого и в социальном плане. Понятно, что в данном случае речь не идёт о «подлинно жизненном» изображении. Не приуменьшая благотворительных заслуг святого, подчеркнём, что его социальная деятельность в легенде идеализирована и типизирована. Об этом свидетельствует не только громадное имущество церкви во времена Меровингов, но и прежде всего тот факт, что в церковную литературу проникли «антисоциальные» мотивы. Некоторые агиографы как о вполне естественном рассказывают о невольниках, принадлежавших святым. Passio Thrudperti (нач. X века) (см. прим. 22) рассказывает о довольно примечательной смерти указанного святого: он был убит своим же невольником, которого отягощал чрезмерной работой, и, таким образом, обрёл мученический венец.

Такого рода сообщения в легендах единичны, поскольку противоречат общим типам и обычным топосам. Но именно их присутствие и доказывает тот факт, что социальные мотивы, которые встречаются в агиографии в столь ярко выраженном виде, преображены в топосы и выполняют особую функцию.

\section{ЛИТЕРАТУРА}

1. Турский, Г. История франков / Г. Турский. - М.: Наука, 1987. - 464 с.

2. Великий, Афанасий Творения. В 4 т. Т. 3. Житие Антония / Афанасий Великий. - М.: Издание СпасоПреображенского Валаамского монастыря, 1994. - С. 178-250.

3. Сульпиций Север Житие Мартина Турского / Сульпиций Север. - М.: РОССПЭН, 1999. - С. 220-251.

4. Тертуллиан Квинт Септимий Флорент. Избранные сочинения / Тертуллиан Квинт Септимий Флорент. М.: Прогресс, 1994. - 448 c.

5. Corpus scriptorum ecclesiasticonun Latinorum (Wien $1866 \mathrm{ff}$.).

6. Hellmann, Siegmund (ed.). Ps.-Cyprianus. De xii abusiuis saeculi / Hellmann, Siegmund // Texte und Untersuchungen zur Geschichte der altchristlichen Literatur 34. - Leipzig, 1909. - P. 40-56.

7. Liber historiae Francorum // Monumenta Germaniae Historica. Scriptores rerum Merovingicarum. T. II. - Hannoverae: Impensi Bibliopolii Hahniani, 1888. - P. 215-328.

8. Migne, J. P. Patrologia Latina (Paris 1844 ff.) / J. P. Migne.

9. Scriptores rerum Merovingicarum // Monumenta Germaniae Historica (Hannoverae: Impensi Bibliopolii Hahniani, $1888 \mathrm{ff}$.).

\section{ПРИМЕЧАНИЯ}

1. Это особенно заметно в «Житии Мартина Турского» Сульпиция Севера, где данные мотивы занимают особое место. Кроме этого отметим Vita Caesarii ep. Arelat. (SS rer. Mer. III, P. 433-501; 549 год.); Vita Boniti ep. (Ibid. VI, P. 110-139; перв. пол. VIII века; оно особо интересно тем, что здесь народные мотивы совершенно отсутствуют, социальные же выражены особенно ярко); Vita Ansberti ep. (Ibid. V, P. 613-643; 800 год).

2. См.: Тертуллиан. О терпении, С. 325: «Он (то есть Христос - А. Д.) всегда оправдывает бедных, а богатых осуждает».

3. См.: Augustin Sermo 197, 2 (Migne PL 38, 1023): «Не избрал (Христос - А. Д.) царей или сенаторов, или философов, или ораторов: но избрал плебеев, бедняков, неучёных, рыбаков».

4. Hieronimys. Contra Vigilantium C. 14 (Migne PL 23, 350): «Ибо блаженными зовутся не просто нищие, но нищие духом».

5. Sermo 85 (Migne PL 38, 521).

6. Pseudo-Cyprianus, P. 49 ff. Данное произведение создано в VII веке в Ирландии. Образ «надменного нищего» появляется уже в Ветхом Завете (Сир. 25, 3).

7. См.: Тов. 12, 9; Сир. 3, 33; позднее в этом же духе истолковывался фрагмент из Евангелия от Луки (Лк. 11,41$)$. Иногда понятие eleemosyna толковалось расширительно и приближалось к понятию «доброе дело».

8. Это имеет место уже в знаменитой истории о разрезании плаща св. Мартином, когда он ещё служил солдатом (Жит. Март. гл. 3; С. 227-228); этот же святой согласно Dial. II, 1 (CSEL 1, P. 180 f.) отдаёт нищему свою одежду и остаётся совершенно голым. B Vita Caesarii ep. Arelat. I, 3 (SS rer. Mer. III, P. 458; перв. пол. 
Донченко А. И.

ПСЕВДОНАРОДНЫЕ И СОЦИАЛЬНЫЕ СЮЖЕТЫ В МЕРОВИНГСКОЙ АГИОГРАФИИ (ЧАСТЬ II)

VI века) рассказывается о том, как святой, будучи ещё мальчиком, часто отдавал свою одежду нищим; сходную ситуацию мы видим в II Vita s. Medardi c. 2 (AA IV-2, P. 68; нач. VII века) и Vita Trudonis conf. C. 2 (SS rer. Mer. VI, P. 276 f.; VIII век.). Несмотря на запрещение своего господина, святой (Vita Vincentiani conf. C. 8-9; Ibid. V, Р. 118) отдаёт свою одежду нищему.

9. См., например: Greg. Tur. Vitae patrum XIII, 1 (SS rer. Mer. I-2, P. 715 - Люпицин); Ibid. XV, 1 (Ibid., P. 721 - Сенох); Ibid. XIX, 1 (Ibid., P. 736 f. - Монегунда); Vita Richarii sac. C. 3 (Ibid. VII, p. 446; VIII век); Vita Pardulfi abb. C. 3 (Ibid., p. 26; VIII век). См. также каролингское Vita Sigiramni abb. C. 24 (SS rer. Mer. IV, P. 620).

10. Vita Sigiramni abb. Longoretensis (SS rer. Mer. IV, Р. 603-625). К сожалению, данное житие сохранилось только в каролингской переработке, однако оно, несомненно, меровингское.

11. 2 Фес. 3, 10.

12. См.: Жит. Антония. гл. 3, 50, 53 (С. 181, 219, 221). В Галлии: Vita Germani ep. Autissiod. C. 3 (SS rer. Mer. VII, P. 252 f.; 480 год - святой сам себе пёк хлеб); Greg. Tur. Vitae patrum I, 2 (Ibid. I-2, P. 665 - при основании монастыря и в самом монастыре); Ibid. XVIII, 1 (Ibid., P. 734 - то же самое); Ibid. XII, 1 (Ibid., P. 712 корчевание); Ibid. VIII, 1 (Ibid., Р. 691 - св. Ницетий трудится сначала в отчем доме, затем, будучи уже в сане дьякона, за пределами монастыря). О роли труда в монастырской общине см. также: Vita Johannis abb. C. 4, 7, 16, 18 (Ibid. III, P. 508, 509 f., 514, 516). Эти примеры можно умножать до бесконечности, поскольку их содержат все монастырские жития. Монахи сами настаивают на том, чтобы все работали (ср.: Greg. Tur. Vitae patrum XI, 1; Ibid. I-2, P. 709).

13. Здесь она выглядит, скорее, как проклятие или наказание.

14. См., например, притчу Нафана об овце бедняка в 2 Цар. 12, 1-6. Часто социальные проблемы затрагивали пророки (особенно, Исайя).

15. Часто подобного рода рассказы носили подчёркнуто церковный характер, то есть они должны были устрашать могущественных людей, которые замахивались на церковное имущество; в этом отношении весьма показательно Greg. Tur. Virt. Martini I, 29 (SS rer. Mer. I-2, Р. 602). Особенно стали популярны истории о наказании могущественных притеснителей бедных, начиная с X века.

16. См., например: Vita Willibrordi archiep. C. 15, 20 (SS rer. Mer. VII, P. 129, 131 f.).

17. См.: Vita Dalmatii ep. Ruteni C. 3 (SS rer. Mer. III, P. 345; VII-VIII вв.). Святой пришёл в Нарбон, «где суровость суда подвергла подсудимого заключению и он, обречённый смерти, пребывал в тюрьме. И вот пришёл святой и напомнил о том, что не раз по человеческому суду некоторые преступники случайно освобождались, а другие, невиновные, жестоко убивались, а часто бывало и так, что страдали без разбора как невиновные, так и преступники». Затем следует сообщение о чудесном освобождении заключённого.

18. То есть укрытие в церкви вовсе не означает, что невольник получал свободу; он лишь должен был быть освобождён от тяжёлых телесных наказаний.

19. Обычно посредством чар.

20. См.: Григ. Тур. Ист. фр. VI, 8; С. 164-165; здесь освобождению преступника препятствует даже сам народ.

21. См.: Greg. Tur. Gloria mart. C. 72 (SS rer. Mer. I-2, Р. 536); данное чудо приписывается мученику Квинтину.

22. Passio Thrudperti mart. Brisgoviensis (SS rer. Mer. IV). - P. 352-363. 